\title{
A Comparative Study of ICTAD 1989 and ICTAD 2002 Standard Conditions of Contract for Building and Civil Engineering Works
}

\author{
Raufdeen Rameezdeen \\ Raveendranathan Shiyamasuntharan
}

\begin{abstract}
The standard forms of contract are prepared with the intention of allocating and standardizing the rights and obligations of the contracting parties and providing guidance to proper management of project objectives. Thus, the standard forms of contract play a dominant legal and management role in construction projects. This holds the fact that standard forms of contract should promote good project management. The significant attributes of a good management of contract are; clear definition and fair allocation of rights and obligations of the contracting parties, well-emphasized time, cost and quality control, and clear boundaries to the powers of the Engineer. The drafting of standard forms of contract should therefore address the above attributes to ensure good project management.
\end{abstract}

In Sri Lanka, standard forms of contract for construction are published by the Institute for Construction Training and Development (ICTAD). The first version of the standard form of contract was prepared in 1986 and revised in 1989. After many years of practical experience it has been reviewed and a new edition was published in January 2002. This paper examines the content of both editions and provides a comparison of the features of project management. The 2002 edition promotes good management of contract by having a proactive approach compared to the reactive approach in the 1989 edition. However, the two documents do not differ significantly in terms of how they deal with project management attributes.

\section{Introduction}

Bunni (1991) emphasized the necessity of standard forms of contract in almost every agreement because of the complexity of commercial activities. Taking into account the basic differences of construction from other commercial activities, Forward (2002) claimed that construction by nature is a relatively complex process and has long demanded contracts of greater sophistication than many other commercial activities. The FIDIC (1989) specified standardization as essential both in technical and administrative matters, for the satisfactory completion of projects of building and civil engineering construction holds quite true. The FIDIC (1989) further provided the advantages tangible in using detailed contract provisions based upon a standard form of contract, holding a reasonable balance between the requirements and interests of the parties and in particular fair allocation of risks and responsibilities. The use of standard Conditions of Contract will not only facilitate the successful completion of a contract, but also result in lower prices, as tenderers will be familiar with the conditions that will apply under the contract. Tenderers would not need to make financial provision for contract conditions with which they are not familiar and consequences of which they may have difficulty of assessing (FIDIC, 1989).
The primary intention of introducing the standard forms of contract into the construction industry was to improve the fairness and standardize the rights and obligations of contracting parties. However, Forward (2002) identified two difficulties. First, the number of standard forms has proliferated. Secondly, sufficient dissatisfaction exists with many of those put forward. Bunni (1991) expressed that the knowledge accumulated through experience and the recurrent use over a long period of time has brought about revisions and modifications in construction standard forms with the aim either of achieving greater certainty in the intention of the wording or of providing a response to the needs of the parties and/or society.

In Sri Lanka, standard forms of Contract for construction are published by the ICTAD and they largely imitate the widely accepted international forms such as FIDIC and World Bank. The first edition of the Conditions of Contract for Works of Building and Civil Engineering was published in September 1986 and was largely based on the FIDIC Conditions of Contract $3^{\text {rd }}$ edition. Afterwards, the ICTAD (1986) was revised to incorporate the recommendations for development of domestic construction contractors in 1988. The revised edition 
was published in January 1989. The ICTAD (1989) was used for a long time and criticisms were levied during that time for imperfectness on various aspects including the complexity of language that led to ambiguity. Attempt had been made by the ICTAD to overcome such problems. A steering committees and a sub committee were appointed for the review of ICTAD publications. The outcome of the committees was the Standard Bidding Document (SBD) for Procurement of Works that consists of new Conditions of Contract, which was published in January 2002. This document is based on World Bank Standard Bidding Document for Smaller Works. The. ICTAD (2002) supersedes the ICTAD Conditions of Contract for Woks of Building and Civil Engineering 1989 edition.

\section{Research Question}

The standard forms of contract plays a dominant legal and management role in construction projects. This holds the fact that standard forms of contracts should promote good project management. The significant attributes of a good management of contract are;

\section{1. clear definition and fair allocation of rights and obligations of the contracting parties,}

2. well-emphasized time, cost and quality control, and

\section{3. clear boundaries to the powers of the Engineer.}

The drafting of standard forms of contract should therefore address the above attributes to ensure good project management. This paper aims to compare the two editions of the ICTAD Conditions of Contract to understand how each edition dealt with above attributes. This understanding will help in a smooth transition from old to the new edition.

\section{Research Methodology}

The research required a detailed study of the two documents to identify the presence of above stated attributes. To fulfill this purpose a desk study was carried out on the old and new Conditions of Contract and allied literature. Content analysis, which has been defined as a systematic research method for analyzing textual information in a standardized way that allows evaluators to make inference about that information (Weber, 1990). was used to classify the key ideas in contract documents. (Weber, 1990) expressed that a central idea in content analysis is that the many words of the text are classified into much fewer content categories. In this way, the researchers classify the key ideas in a written communication. The classification process, called "coding" consists of marking text passages with short alphanumeric codes. This creates "categorical variables" that represent the original information that can then be analyzed by standard statistical methods (Holsti, 1969). In order for the classification of a document, its key ideas, in the form of themes, issues, topics and so on have to be identified. Further, the frequency of such statements or their intensity can be measured to make inference about the text. The central assumption of content analysis is that the greater the occurrence of the category, the more important it is as part of the text.

Content analysis has been previously used in studies relating to employee and employer perceptions of occupational health and safety risk in construction (Holmes and Gifford, 1996) and employee perceptions of solid waste management systems (Lingard et.al., 1998). The decision to use content analysis as the methodology arose in view of the fact that content analysis can well address the descriptive research question explained in section 2. (Weber, 1990) holds up the selection by expressing that when the subject matter is textual and the evaluation questions lend themselves to numerical descriptions or comparisons, content analysis is usually a good choice. Since content analysis is systematic, it helps to learn more about the issues under examination. It has a structured form that allows extracting relevant information more consistently than casually reading the same document. A sentence or a set of sentences explaining the attributes listed above in the research question has been categorized and taken as a variable in the content analysis. Once the variables were defined and the textual data were selected, the selection of recording was considered to represent the text in order to pool them into variable categories. The defined variables themselves possess the nature to be determined through "themes" rather than word, word sense, sentence or paragraph as the variables delineate a single idea according to the research question specified above. (Holsti , 1969) describes a "theme" as "a single assertion about some subject matter". The boundary of a theme therefore defines a single idea. This research was not restricted to the semantic boundaries of sentences or paragraphs.

In order to link the data back to the research question, the frequency count of a category was selected as the analysis option. It is the most common method for measuring content and specifically when the categories are nominal (Reynolds, 1984). The coding, the essence of content analysis, made the bridge from text to numbers. In order to draw inferences from the text, the frequency of the "themes" were counted and tabulated.

\section{A General Comparison of the New and Old Editions}

The 1989 version of the Conditions of Contract was based on FIDIC $3^{\text {rd }}$ edition, which was used and widely accepted by many including the World Bank and regional development banks. Even though the original FIDIC $3^{\text {rd }}$ edition has been revised more than once to reflect the current developments in modern project management, 
ICTAD 1989 edition was not updated since its publication. That was the main reason why ICTAD started reviewing the Conditions of Contract and decided to base the revision on the World Band Standard Bidding Document (SBD). The Conditions of Contract incorporated in the World Bank SBD is based on the New Engineering Contract (NEC), which is said to be "flexible and clear and promote good management" (The Institution of Civil Engineers, 1993). Forward (2002) affirmed that the use of NEC responds to the requirements of the twenty-first century, particularly by virtue of the communication requirements and compensation event procedure. The ability to control time, cost and quality parameters is arguably better and easier to balance than other forms of contract. Totterdill (2002) stated that even the 1999 FIDIC contract has been considerably improved and clearly benefited from the layout and style of the NEC. These issues would therefore have stemmed the ICTAD to consider World Bank SBD for adaptation.

When scrutinizing the two forms of contract in detail, following subheadings could be used to highlight the differences in approach between the documents.

\section{i. Contract Philosophy}

ICTAD 1989 edition has been written on the principle that in construction there will always be problems and potential for disputes. Thus, it results in more complex project management procedures, which require a framework that will help to identify and resolve problems or, if the problem develops into a dispute, will ensure that accurate evidence is recorded. On the contrary, the proactive management philosophy of the 2002 edition will encourage co-operation and early joint resolution of problems. This philosophy contrasts with the reactive management approach in the 1989 edition that resulted in problems being dealt with less structured way.

\section{ii. Clarity and Readability}

It was found that, the layout and style of the 2002 edition is much easier to follow. The 2002 edition uses the present tense throughout and more readily understandable commercial language. On the contrary, the 1989 edition uses traditional "shall do" terminology, indicative of semi-legal language.

\section{iii. The Project Management Organization}

The 2002 edition retains the traditional role of the Engineer and the role is clearly defined as being part of the Employer's personnel. The Engineer will be responsible for administering and supervising the execution of work and making initial decisions pertaining to contractual matters such as payments, claims and extension of time while acting within the authority determined in the contract. Both editions allow the Engineer to delegate the duties and responsibilities to the Engineer's representative. However, the major difference is that the Engineer is not required to act in any quasi-arbitrator role. If the Contractor disagrees with the Engineer's decision, the matter can be forwarded to the Adjudicator.

\section{iv. Compensation Events}

The 2002 edition introduces a novel approach for compensation events, which is a procedure for managing events that are at the Employer's risk. The primary purpose of compensation events is to enable the Engineer and the Contractor to manage the consequences of an unexpected situation in a positive way. Sub-Clause 44.1 gives a list of events, including variations, which may give the Contractor an entitlement to additional payment. The 2002 edition also includes a provision in clause 31 , for either the Engineer or the Contractor to call for the other to attend a management meeting. This provision requires the Contractor and the Engineer to co-operate in considering how to overcome any problem and to agree on a solution, which is in the best interest of the project.

\section{v. Early Warning Procedure}

Clause 32 of the 2002 edition places an obligation on the Contractor to notify the Engineer of any matter, which could adversely affect the quality of work, increase in the contract price, or delay in execution of the works. This requirement motivates the parties to identify problems as early as possible and have a proactive approach to find a solution jointly rather than putting off a decision or ignoring their resolution. The procedure adopted in the 1989 edition, which was based on written notices allowed the Contractor to give an advance notice regarding any actual cost or delay and the Contractor submits a detail report of results at a latter date. The Engineer issues any necessary orders and decides upon the Contractor's claim for additional time or payment.

\section{vi. Variations}

The procedures before issuing the instruction and in the valuation of the variation make the fundamental difference between the 1989 and 2002 edition. In the old edition, the Engineer has the authority of issuing an instruction and after the work has been completed the work is valued generally based on the original rates. Under the 2002 edition, the Contractor is required to submit a quotation, or alternative quotations, for the proposed variation. The Engineer assesses the quotation before the variation is ordered. If the quotation is acceptable the Contractor is paid this quotation. If the quotation is unreasonable the variation shall be ordered based on the Engineer's own forecast. Nevertheless in case of urgency, at the discretion of the Engineer no quotations shall be given and the variation shall be treated as a Compensation Event. However, the Contractor shall not be entitled to additional payment for costs that could have been avoided by giving early warning. 


\section{vii. Resolution of Disputes}

Both editions deal with dispute resolution. The 1989 edition provides Arbitration as the dispute resolution option, whereas the 2002 edition requires that a dispute be first referred to the Adjudicator. If this fails then it is referred to arbitration in accordance with the Arbitration Act No. 11 of 1995. This enables speedy resolution of disputes at the very early stages of its initiation.

\section{viii. Payment Procedure}

The new edition retains the traditional payment procedure as the Contractor is paid for the quantity of the work done at the rate in the Bill of Quantities for each item. However, it too failed to give recognition to the Standard Method of Measurement for the preparation of the Bill of Quantities and as a constituent of the contract document.

\section{Results of the Content Analysis}

The results of the content analysis are summarized at Table 1 in numerical terms using the frequency counts of each variable. The percentages included in Table 1 provide the relative emphasis of a variable in terms of its frequency of occurrence in the document and show how each attribute under consideration is dealt in the documents. The attribute, "clear definition and fair allocation of rights and obligations of the contracting parties" is analyzed using two variables, namely, Employers Obligation and Contractors Obligations. The second attribute "well-emphasized time, cost and quality control" has three variables, namely time, cost and quality control. The third attribute "clear boundaries to the powers of the Engineer" has only one variable. The 1989 edition has in total 370 themes related to these attributes, while the 2002 edition has only 214 . There are 76 and 69 themes, which are not related to the project management attributes under consideration in the old and new editions respectively. As such the total number of themes of the old document is 446 , compared to 283 themes of the new document.
In the 1989 edition the Contractors Obligations has the highest theme count followed by the Engineers Power, Cost Control, Employers Obligations, Time Control, and Quality Control. Contractors Obligations count is more than double that of the Employers Obligations. Coverage of Cost Control is very high compared to Time and Quality control. In fact, Cost Control count is more than the total of the count of Time and Quality Control.

The 2002 edition has the same order of priority of variables. However, the ratio of Contractors Obligations to Employers Obligations has reduced indicating a shift of responsibility towards the Employer. One of such is the transfer of risk of ground conditions and associated site investigation data to the Employer in the new edition.

The count for the Engineer's power indicates a moderate increase in the new edition and hence, more interaction of the Engineer with the contract. As provided in the FIDIC. (1989) the Engineer's duties generally include instructions relating to the management of contract and changes in the nature and extent of work, the cost thereof and the time for completion. Therefore, the increase in the content related to powers vested on Engineer, though it is modest, will streamline the management of project in a more clear-cut way than the old edition.

The evaluation of the emphasis on time, cost and quality control shows that the new edition offers better time control than the old edition. This is evident in clause 27, which provides better definition of programme content; requires detail supportive documentation; specifies frequent revision; etc..

It is apparent from the total of 283 themes against 446 as given in Table 1 that there is a considerable data reduction in the new edition. This is due to elimination of several redundant clauses contained in the previous edition. The usage of plain language in place of semilegal language too would have contributed to the data reduction.

Table 1: Frequency of Themes on the Selected Variable Categories

\begin{tabular}{|l|c|c|c|c|}
\hline \multirow{2}{*}{ Variable Categories } & \multicolumn{2}{c|}{ Old edition (1989) } & \multicolumn{2}{c|}{ New edition (2002) } \\
\cline { 2 - 5 } & Count & Percent & Count & Percent \\
\hline Employer's Obligations & 53 & 14 & 33 & 15 \\
\hline Contractor's Obligations & 122 & 33 & 61 & 29 \\
\hline Engineer's Power & 95 & 26 & 60 & 28 \\
\hline Time Control & 20 & 6 & 19 & 9 \\
\hline Cost Control & 62 & 17 & 33 & 15 \\
\hline Quality Control & 18 & 5 & 8 & 4 \\
\hline $\begin{array}{l}\text { Total of themes related to } \\
\text { project management attributes }\end{array}$ & 370 & 100 & 214 & 100 \\
\hline Other themes & 76 & & 69 & \\
\hline Total themes in the document & 446 & & 283 & \\
\hline
\end{tabular}




\section{Discussion}

The general comparison and the content analysis explained earlier highlighted the strengths of the 2002 edition compared to the 1989 edition. However, following weaknesses and/or technical faults exist in the 2002 edition.

i . Typographical error in Contract Data under Clause 48.1. Retention amount is stated as $10 \%$ of the "initial contract price". However, this should read as $10 \%$ of the "certified monthly payment".

ii.Inconsistency of use of capital letters for defined terms throughout the document.

iii.Starting date of recovery of advance payment is not dealt in the advance payment clause (Clause 51).

iv. The clause dealing with Arbitration (Clause 25.3) is not adequate. For example the clause does not specify the type of disputes that should be referred to arbitration.

v. "Provisional Sums" and "Nominated Subcontractors" are dealt under the sectional heading "Finishing the Contract".

vi.The term "Nominated subcontractor" is not well defined in clause 63 . The clause is silent on the appointment and the responsibilities of nominated subcontractors.

vii.A fixed attendance fee of $8 \%$ on nominated subcontractor's work is inappropriate as given in Contract Data of clause 63. The attendance fee should be decided according to the nature of subcontractor's work.

In section $\mathbf{4}$ of this paper, a general comparison was made between the two documents. The section 5 further highlighted the differences in term of content they cover for identified project management attributes. As such, throughout this paper the two documents were compared one against the other. However, it is appropriate to ask the question "is there a significant difference between the 2002 and 1989 edition in terms of Project Management attributes?"

Therefore, Person's Chi-Square test (Tan, 2002; Snedecor and Cochran, 1989) was used to determine the significance of the difference between the two editions based on the results of content analysis. The Null Hypothesis, $H_{0}$, was considered as no difference between the documents. The alternative hypothesis, $H_{1}$, was that the new edition differs significantly from the old edition. The Chi-Square test compares the obtained frequencies with the expected frequencies of the new document as per the hypothesis. For each variable category, the expected frequency is given as follows.
$N_{p i}=f_{e j}=$ expected frequency

Where, $p_{i}$ is the relative frequency for category $j$ dictated by the hypothesis.

The Table 2 below provides the obtained and expected frequencies for each category for the new edition.

Table 2: Comparison of obtained and expected frequencies

\begin{tabular}{|c|c|c|}
\hline Category & $\begin{array}{c}\text { fo } \\
\text { (Obtained } \\
\text { frequencies) }\end{array}$ & $\begin{array}{c}\text { fe } \\
\text { (Expected } \\
\text { frequencies) }\end{array}$ \\
\hline 1 & 33 & 30 \\
\hline 2 & 61 & 70 \\
\hline 3 & 60 & 55 \\
\hline 4 & 19 & 13 \\
\hline 5 & 33 & 36 \\
\hline 6 & 8 & 10 \\
\hline & 214 & 214 \\
\hline
\end{tabular}

The Chi-Square statistic is:

$X^{2}=\frac{\sum\left(f o_{i}-f e_{j}\right)^{2}}{f e_{j}}$

Applying values in Table 2 provides:

$X^{2}=4.18$

The number of degrees of treedom is j-1, i.e. 6-1=5

Chi-Square table shows that for 5 degrees of freedom, a value of 11.07 cuts off the upper 0.05 of the distribution, and a value of 15.09 corresponds to the upper 0.01 . Since $X^{2}$ is 4.18 the null hypothesis has to be accepted even at 0.05 and 0.01 level. As such it can be concluded that there is no significant difference between the two editions. This signifies that even though the two editions differ in approach and style, the contents do not differ much.

\section{Conclusions}

Fair allocation of rights and obligations of the contracting parties, powers of the Engineer, sound emphasis on time, cost and quality control are very important requirements of a construction contract to ensure good project management. This paper compared the 1989 and 2002 editions of the ICTAD standard conditions of contract to discern the differences in above mentioned attributes.

The study revealed that the 2002 edition provides a proactive management of contract through some new 
provisions such as early warning and compensation event against the reactive approach in the previous edition. This approach encourages co-operation and early joint resolution of problems rather than the problem being dealt with less structured way as in the earlier edition. Further the improved layout and style in the new edition has potential to attract new users on the ground of enhanced clarity and readability.

The content analysis showed that the shift from 1989 edition to 2002 carries fewer obligations for Contractors and more obligations for the Employer. It seems that the new edition of the ICTAD condition of contract is trying to strike a balance of obligations between the contracting parties. In addition, an increased emphasis on time control could be observed in the 2002 edition. This may be as a reaction to the bad record of time overruns observed in almost all projects in Sri Lanka. As, such, increased emphasis on time control is a noteworthy development in the right direction. Finally, it can be concluded that the 2002 edition promotes good management of contractin a clear-cut way by having a proactive approach compared to the reactive approach found in the 1989 edition. However, the two documents do not differ significantly in terms of how they deal with Project Management attributes.

\section{References}

Bunni. N.G (1991), "The FIDIC Form of Contract: The fourth edition of the Red Book", BSP Professional Book, London.

FIDIC (1989), 4" ed., "Guide to the Use of FIDIC Condition of Contract for Works of Civil Engineering Construction", Federation Internationale Des Ingenieurs Conseils, Lausanne, Switzerland.

Forward. F (2002), "The NEC Compared and Contrasted with JCT 98", in: Forward.F. (ed), The NEC Compared and Contrasted, Thomas Telford, London.

Holmes, N. and Gifford, S., (1996), "Social meanings of risk in Occupational Health and Safety: Consequences for risk control", Journal of Occupational Health and Safety Australia and New Zealand, 12, 443-450.
Holsti, O.R. (1969) "Content Analysis for the Social Sciences and Humanities" Reading, Mass, Addison-Wesley.

ICTAD (1986), "Condition of Contract for Works of Building and Civil Engineering", Institute of Construction Training and Development, Sri Lanka.

ICTAD (1989), "Condition of Contract for Works of Building and Civil Engineering", Institute of Construction Training and Development, Sri Lanka.

ICTAD (2002), "Standard Biding Document, Procurement of Works", Institute of Construction Training and Development, Sri Lanka.

Lingard, H., Graham, P. and Smithers G., (1998), "Employee perceptions of solid waste management system operating in a large Australian contracting organization: implications for company policy implementation", Construction Management and Economics, 18, 383-393.

Reynolds. H.T. (1984), "Analysis of Nominal Data", $2^{\text {nd }}$ ed., Newbury Park, Calif.: Sage.

Snedecor G. W. and Cochran W.G., (1989), "Statistical Methods", $8^{\text {th }}$ ed., lowa State University Press, lowa.

Tan W., (2002), "Practical Research Methods", Prentice Hall, Singapore.

The Institution of Civil Engineers, (1993), "The New Engineering Contract Guidance Notes", Thomas Telford, London.

Totterdill B. (2002), The NEC Compared and Contrasted With FIDIC", in Forward.F. (ed), The NEC Compared and Contrasted, Thomas Telford, London.

Weber R.P. (1990), "Basic Content Analysis", $2^{\text {nd }}$ ed., Newbury Park, Calif.: Sage. 